\title{
Predictors of Conduction Disturbances after Transcatheter Aortic Valve Implantation with Balloon-expandable Valve for Bicuspid Aortic Valve Stenosis
}

\author{
Hirokazu Miyashita ${ }^{1}$, Noriaki Moriyama ${ }^{2}$, Futoshi Yamanaka ${ }^{2}$, Shigeru Saito ${ }^{2}$, Heidi \\ Lehtola $^{3}$, Jarkko Piuhola ${ }^{3}$, Matti Niemelä ${ }^{3}$, and Mika Laine ${ }^{1}$ \\ ${ }^{1}$ Helsinki University Central Hospital \\ ${ }^{2}$ Shonan Kamakura General Hospital \\ ${ }^{3}$ Oulu University Hospital
}

December 5, 2021

\begin{abstract}
Objective: The implantation depth and membranous septum (MS) length are established as the predictors of new-onset conduction disturbance (CD) after transcatheter aortic valve replacement (TAVR) for tricuspid aortic valve (TAV) stenosis. However, little is known about the predictors with bicuspid aortic valve (BAV). This study investigated the role of MS length and implantation depth in predicting CD following TAVR with a balloon-expandable valve in patients with BAV. Methods and results: This retrospective study analyzed 169 patients who underwent TAVR for BAV with balloon-expandable valve, and TAV cohort was established as a control group using propensity score (PS) matching. The primary endpoint was in-hospital new-onset CD (new-onset left bundle branch block or new permanent pacemaker implantation). New-onset CD developed in 37 patients (21.9\%). Multivariate analysis revealed severe LVOT calcification (Odds ratio [OR]: $5.83,95 \%$ confidence interval [CI]: 1.08 $-31.5, \mathrm{p}=0.0407)$ and implantation depth - MS length (OR: 1.30, 95\% CI: $1.12-1.51, \mathrm{p}=0.0005)$ as the predictors of new-onset CD within BAV cohort. The matched comparison between BAV and TAV groups showed similar MS length (3.0 vs $3.2 \mathrm{~mm}, \mathrm{p}=0.5307)$, but valves were implanted deeper in BAV than TAV group (3.9 vs 3.0mm, $\mathrm{p}<.0001)$. New-onset CD was more frequent in patients having BAV $(22.3 \%$ vs $13.9 \%, \mathrm{p}=0.0458)$. Conclusion: The implantation depth - MS length, and severe LVOT calcification predicted new-onset CD following TAVR in BAV with balloon-expandable valve. High implantation technique could be considered to avoid new-onset CD in BAV anatomy.
\end{abstract}

Predictors of Conduction Disturbances after Transcatheter Aortic Valve Implantation with Balloon-expandable Valve for Bicuspid Aortic Valve Stenosis

Hirokazu Miyashita ${ }^{1}$, Noriaki Moriyama ${ }^{2}$, Futoshi Yamanaka ${ }^{2}$, Shigeru Saito ${ }^{2}$, Heidi Lehtola ${ }^{3}$, Jarkko Piuhola $^{3}$, Matti Niemelä ${ }^{3}$, Mika Laine ${ }^{1}$

${ }^{1}$ Department of Cardiology, Heart and Lung Center, Helsinki University and Helsinki University Central Hospital, Helsinki, Finland

${ }^{2}$ Department of Cardiology, Shonan Kamakura General Hospital, Kamakura, Japan

${ }^{3}$ Department of Cardiology, Oulu University Hospital, Oulu, Finland

E-mail address :pastello41@gmail.com(Hirokazu Miyashita),e2718nm@gmail.com (Noriaki Moriyama),futoshi.yamanaka@gmail.com(Futoshi

Saito),heidi.m.lehtola@gmail.com(Heidi

Yamanaka),transradial@kamakuraheart.org(Shigeru

la),matti.niemela@ppshp.fi(Matti Niemelä)Mika.Laine@fus.fi (Mika Laine) 


\title{
Disclosure statement
}

Dr. Miyashita has nothing to disclose. Dr. Moriyama is a clinical proctor of Edwards Lifesciences (SAPIEN) and Boston Scientific (ACURATE neo and LOTUS Edge). Dr. Yamanaka has nothing to disclose. Dr. Saito reports lecture fees from Edwards Lifesciences and Medtronic and is a clinical proctor of Edwards Lifesciences (SAPIEN) and Medtronic (Evolut). Dr. Lehtola has nothing to disclose. Dr. Piuhola reports a lecture fee from Edwards Lifesciences. Dr. Laine reports non-regulatory research grants from Teleflex and consulting fees from Edwards Lifesciences, Boston Scientific, and Medtronic.

\section{Funding: None}

\section{Acknowledgements: None.}

Total word counts: 5193

\section{Corresponding author :}

Mika Laine, MD, PhD, Adjunctive Professor of Cardiology

Heart and Lung Center,

Helsinki University and Helsinki University Central Hospital,

Haartmaninkatu 4, 00290, Helsinki, Finland

Telephone: +358504279008 , Fax: +358504270352

E-mail: Mika.Laine@hus.fi

\begin{abstract}
Objective: The implantation depth and membranous septum (MS) length are established as the predictors of new-onset conduction disturbance (CD) after transcatheter aortic valve replacement (TAVR) for tricuspid aortic valve (TAV) stenosis. However, little is known about the predictors with bicuspid aortic valve (BAV). This study investigated the role of MS length and implantation depth in predicting CD following TAVR with a balloon-expandable valve in patients with BAV.
\end{abstract}

Methods and results: This retrospective study analyzed 169 patients who underwent TAVR for BAV with balloon-expandable valve, and TAV cohort was established as a control group using propensity score (PS) matching. The primary endpoint was in-hospital new-onset CD (new-onset left bundle branch block or new permanent pacemaker implantation). New-onset CD developed in 37 patients (21.9\%). Multivariate analysis revealed severe LVOT calcification (Odds ratio [OR]: $5.83,95 \%$ confidence interval $[\mathrm{CI}]: 1.08-31.5, \mathrm{p}=$ 0.0407 ) and implantation depth - MS length (OR: 1.30, 95\% CI: $1.12-1.51, \mathrm{p}=0.0005)$ as the predictors of new-onset CD within BAV cohort. The matched comparison between BAV and TAV groups showed similar MS length (3.0 vs $3.2 \mathrm{~mm}, \mathrm{p}=0.5307$ ), but valves were implanted deeper in BAV than TAV group (3.9 vs $3.0 \mathrm{~mm}, \mathrm{p}<.0001)$. New-onset CD was more frequent in patients having BAV (22.3\% vs $13.9 \%, \mathrm{p}=0.0458)$.

Conclusion: The implantation depth - MS length, and severe LVOT calcification predicted new-onset CD following TAVR in BAV with balloon-expandable valve. High implantation technique could be considered to avoid new-onset CD in BAV anatomy.

\section{Key words:}

Aortic stenosis, Bicuspid aortic valve, Conduction disorder, Implantation depth, Membranous septum length, Transcatheter aortic valve replacement

\section{Introduction}

Transcatheter aortic valve replacement (TAVR) has been established as a treatment of symptomatic aortic stenosis (AS) $(\mathbf{1}, \mathbf{2})$, and its benefit has been extended to low-surgical risk patients $(\mathbf{3}, \mathbf{4})$. Bicuspid aortic valve $(\mathrm{BAV})$ is estimated to have a prevalence of around $0.5 \%(\mathbf{5})$ and $0.8 \%$ in the male population $(6$ 
) and is associated with the risk of developing aortic stenosis due to underlying abnormal valve geometry and mechanical stress $(\mathbf{7})$. Although AS patients with BAV were excluded from early pivotal randomized studies $(\mathbf{1}-\mathbf{4})$, the evidence concerning TAVR for BAV is important because of the high prevalence of BAV among younger AS patients. Recent studies have reported comparable prognosis, hemodynamic results, and the safety of TAVR for BAV stenosis as compared to tricuspid aortic valve (TAV) stenosis (8 - 10 ). In addition, a randomized study showed the safety of TAVR for BAV in comparison with surgical aortic valve replacement (SAVR) (11).

Conduction disturbance (CD) including new permanent pacemaker implantation (PPI) and complete left bundle branch block (LBBB) have been reported as major complications following TAVR, and they are also associated with the risk of increased mortality and hospital readmissions (12 - 14). To avoid TAVR-related $\mathrm{CD}$, several techniques such as double-cusp-view implantation with self-expandable THV (15 ) and high implantation technique with balloon-expandable THV (16 ) have been proposed. In addition, membranous septum (MS) length represents an anatomic surrogate of the distance between the aortic annulus and the bundle of HIS, and MS length is inversely related to the risk of CD following TAVR (17). Moreover, other studies reported, that both MS length and implantation depth are associated with CD (18, 19 ). However, less is known about the impact of the implantation depth and the MS length on CD outcomes in bicuspid anatomy

This study aimed to investigate the impact of MS length and implantation depth in predicting CD following TAVR with balloon-expandable valve in patients with BAV.

\section{Methods}

\section{Patient selection}

This study was a retrospective registry from 3 centers (Helsinki University Hospital, Finland; Oulu University Hospital, Finland and Shonan Kamakura General Hospital, Japan). Patients with BAV stenosis who underwent TAVR were eligible for the study. Out of 195 eligible patients from 3 centers, 26 patients (intraprocedural death: 0, implantation failure: 2 , poor CT image quality: 1 , poor angiogram quality: 5 , prior PPI: 17) were excluded from the analysis (Figure 1 ). After exclusion, 169 patients remained for further analysis. BAV morphology was confirmed by pre-procedural MDCT and determined using the Sievers classification (20 ). TAV cohort was established to compare with BAV cohort by using propensity score (PS) matching. The inclusion criteria of TAV cohort were patients with TAV stenosis who underwent TAVR at Helsinki university hospital. Exclusion criteria were the same as the BAV cohort. THV size was selected based on the integration of preprocedural MDCT assessment including annulus area size and inter-commissural distance (ICD) at $4 \mathrm{~mm}$ above the annulus by the multidisciplinary heart team at the individual hospital. This study was conformed to the Declaration of Helsinki and approved by the Institutional Review Board in Helsinki.

\section{Definition and outcome measures}

The MS was defined as the thinnest part of the interventricular septum on the perpendicular annular plane image, and MS length was measured as the distance from the annular plane to the vertex of the muscular septum in stretched vessel image (18). Leaflet calcification and LVOT calcification severity were semiquantitatively measured as previously defined $(\mathbf{2 1}, \mathbf{2 2})$. The implantation depth was measured with fluoroscopy images by using institutional imaging software. The implantation depth was defined as the distance between the bottom of the non-coronary cusp (NCC) to the ventricular end of the valve stent frame in the final angiogram after the valve deployment (Figure 2 ). The angle of the image was normally perpendicular deployment view, but it can be adjusted by the attending physician.

To evaluate CD following TAVR, we set the primary endpoint as in-hospital new CD (new-onset LBBB or new PPI). The indication of PPI following TAVR was decided by the heart team at each hospital. Also, the hemodynamic outcome measured by ultrasound and in-hospital complications based on VARC-2 criteria (23) were collected. The preoperative risk was evaluated by calculating the Society of Thoracic Surgeons predicted risk of mortality (STS-PROM) score. The baseline characteristics, procedural characteristics, complications, 
and results were compared between the patients without CD and with CD following TAVR. Also, CD and hemodynamic results were compared between the 2 groups based on implantation depth and MS length (implantation depth > MS length and implantation depth [?] MS length groups).

\section{Statistical analysis}

Categorical variables are presented as counts and/or percentages and were compared using the chi-square test or Fischer's exact test if needed. Continuous variables are presented as the mean +- standard deviation and were compared using the Student's t-test or the Wilcoxon rank-sum test based on their distributions. To determine predictors of the endpoint, a logistic regression analysis including baseline and procedural covariates was used to obtain the odds ratio (OR) and $95 \%$ confidence interval (CI) for the development of endpoints. Variables with a p-value $<0.1$ on univariate analysis were included for the multivariate model. All statistical tests were two-tailed. A p-value $<0.05$ was considered statistically significant. To compare the BAV patient group and TAV group, the propensity score matching method was modeled with the following variables: age, gender, body mass index, NYHA class [?]3, STS PROM, hypertension, dyslipidemia, diabetes mellitus, atrial fibrillation, chronic kidney disease, prior coronary artery bypass graft surgery (CABG), right bundle branch block (RBBB), LBBB, first-degree atrioventricular block (AVB), left ventricular ejection fraction (LVEF), SAPIEN 3 ultra, approach site. Statistical analyses were performed using JMP version 14.2 (SAS Institute Inc., Cary, NC, USA).

\section{Results}

Patient characteristics, including baseline CD and anatomical characteristics, are shown in Table 1 . The mean age was $76.8+-6.7$ years old, $53 \%$ were female, and STS PROM was $3.2 \%$. As ECG findings, $8.9 \%$ of patients had RBBB, $8.3 \% \mathrm{LBBB}$, and $24.9 \%$ first-degree atrio-ventricular block. The most prevalent anatomical type was the type $1(158 / 169) 93.5 \%$, the second common type was the type $0(10 / 169) 5.9 \%$, and one patient had the type $2 \mathrm{BAV}(1 / 169) 0.6 \%$. The mean MS length was $3.0+-2.0 \mathrm{~mm}$. Table 1 also presented patient characteristics comparison between the patient without $(\mathrm{n}=132)$ and with $\mathrm{CD}(\mathrm{n}=37)$ after TAVR. There were significant differences in the prevalence of atrial fibrillation (without CD $25.8 \%$ vs. with CD $43.2 \%, \mathrm{p}=0.0394)$, prior stroke $(7.6 \%$ vs. $21.6 \%, \mathrm{p}=0.0295)$, severe leaflet calcification $(74.2 \%$ vs. $94.6 \%, \mathrm{p}=0.0060)$, and severe LVOT calcification $(2.3 \%$ vs. $18.9 \%, \mathrm{p}=0.0011)$, but not in RBBB $(8.3 \%$ vs. $10.8 \%, \mathrm{p}=0.6396)$, first degree $\operatorname{AVB}(22.7 \%$ vs. $32.4 \%, \mathrm{p}=0.2273)$, and MS length $(3.1+-2.0$ mm vs. $2.5+-2.0 \mathrm{~mm}, \mathrm{p}=0.1147)$.

Procedural characteristics and complications are shown in Table 2. There were significant differences in the implantation depth $(3.4+-1.7 \mathrm{~mm}$ vs. $5.5+-3.0 \mathrm{~mm}, \mathrm{p}<0.0001)$, implantation depth - MS $(0.3+-2.5 \mathrm{~mm}$ vs. $3.0+-3.9 \mathrm{~mm}, \mathrm{p}<0.0001)$, and patients with the implantation depth $>$ MS length $(55.3 \%$ vs. $78.4 \%$, $\mathrm{p}=0.0112)$. No significant difference was observed in the incidence of procedure-related complications.

Table 3 presents clinical and hemodynamic outcomes. In the whole bicuspid patient cohort, new PPI was required in $8.3 \%(14 / 169)$, and the incidence of new-onset LBBB or new PPI was $21.9 \%(37 / 169)$. The most common indication for PPI, was a complete AVB, 7 of 14 (50\%), one patient (7.1\%) had Mobitz type 2 AVB, two patients $(14.3 \%)$ had tri-fascicular block and the remaining four patients $(28.6 \%)$ had other indications for PPI. The duration from the TAVR to the PPI is shown inFigure 3 . The other clinical and hemodynamic outcomes were not significantly different (Table 3 ). Figure 4 shows that severe LVOT calcification and implantation depth - MS length were the independent predictors of new-onset CD in the multivariate logistic regression model (severe LVOT calcification: OR 5.83, CI $1.08-31.5, \mathrm{p}=0.0407$; implantation depth -MS length: OR 1.31 per $1 \mathrm{~mm}$, CI $1.13-1.52, \mathrm{p}<0.0001)$. The results of univariate analysis were shown in Supplemental table 1 .

Supplemental table 2 presents multivariate analysis for new PPI after TAVR, which showed baseline RBBB, severe LVOT calcification, and implantation depth - MS length were the predictors of new PPI.Supplemental table 3 represents the comparisons of CD and hemodynamic outcomes between the two groups based on implantation depth and MS length (implantation depth $>$ MS length, and implantation depth [?] MS length groups). The incidence of new-onset CD was greater in implantation depth $>$ MS group, 
while the other hemodynamic outcomes were not significantly different.Figure $\mathbf{5}$ plots the distribution of implantation depth and MS length, and the red color indicates the new-onset CD.

To compare the anatomical characteristics and outcomes between TAVR for BAV and TAV, PS matching was performed to balance the patient characteristics (Table 4 ), which resulted in well-balanced except for estimated glomerular filtration rate (eGFR) and aortic valve area (AVA). There were significant differences in annulus size $(543.7+-96.0 \mathrm{~mm} 2$ vs. $505.5+-100.8 \mathrm{~mm} 2, \mathrm{p}=0.005)$, but not in severe leaflet calcification ( $78.9 \%$ vs. $71.0 \%, \mathrm{p}=0.0994)$, severe LVOT calcification $(6.0 \%$ vs. $7.2 \%, \mathrm{p}=0.6590)$, and MS length $(3.0$ $+-2.0 \mathrm{~mm}$ vs. $3.0+-2.1 \mathrm{p}=0.9038)$. As to procedural characteristics, matched BAV group underwent more pre-dilatation $(61.5 \%$ vs. $28.9 \%, \mathrm{p}<0.0001)$, implanted the THV deeper (implantation depth: 3.9 +- $2.2 \mathrm{~mm}$ vs. $2.9+-1.0 \mathrm{~mm}, \mathrm{p}<0.0001$ ), and had similar rate of procedural complications (Table 5 ). New CD was significantly greater in the patients with BAV than TAV (22.3\% vs. $13.9 \%$, respectively, p = 0.0458), and the other clinical and hemodynamic outcomes were not significantly different between the two groups (Supplemental table 4 ).

\section{Discussion}

This 3-center retrospective registry demonstrated 3 main findings: 1) implantation depth - MS length and severe LVOT calcification were independent predictors of new CD in BAV; 2) when comparing matched BAV and TAV group, MS length was not different, but the incidence of new CD was higher in the patients with BAV , 3) BAV anatomy resulted in a deeper valve implantation, which may explain the increased incidence of $\mathrm{CD}$

\section{Permanent pacemaker implantation rate}

The PPI rate following TAVR for BAV has been reported from $8.0 \%$ to $18 \%$ regardless of the used THV (8, $\mathbf{2 4}$ ) and from $13.1 \%$ to $17.6 \%$ with balloon-expanding SAPIEN 3 THV (11, 25, 26 ). When comparing the incidence of PPI with tricuspid valve, the results were not consistent through the studies; one retrospective study showed a higher PPI rate in the BAV group (5), and the others demonstrated no significant differences between 2 groups $(\mathbf{8}-\mathbf{1 0}, \mathbf{2 7})$. The new PPI rate in the BAV group in our study was in the lower range of previous reports, which was still significantly greater in the matched comparison to TAV group. A possible explanation of low rate of new PPI could be the high implantation (implantation depth: $3.9+-2.2 \mathrm{~mm}$ ), which was higher than that in the previous study (implantation depth: $5.5+-3.7 \mathrm{~mm}$ ). They reported $18 \%$ incidence of new PPI and 41\% incidence of new PPI or new-onset LBBB (24). However, the other studies have not provided implantation depth, thus further studies on the relation between implantation depth and PPI rate in bicuspid aortic valve were warranted.

\section{Predictors of new conduction disturbance in the BAV cohort}

The current study revealed that the implantation depth - MS length and severe LVOT calcification were independent predictors of new CD following TAVR for BAV with SAPIEN 3. The findings on implantation depth and MS length were consistent with prior studies concerning BAV regardless of the THVs $(\mathbf{2 4})$ and with TAV with self-expandable THV (18). In addition, the high implantation technique with balloon-expandable SAPIEN 3 THV achieved lower rate of new conduction disturbances. Furthermore, high implantation was considered safe and provided good hemodynamic results (16). Our study implicates the advantage of high implantation for BAV in terms of reducing CD. The comparison between deeper implantation depth (implantation depth $<$ MS) and higher implantation depth (implantation depth [?] MS) showed a similar complication rate other than CD and similar hemodynamic outcomes.

The impact of LVOT calcification on new CD has been controversial. Although some studies did not find association with LVOT calcification and an increased risk of PPI $(\mathbf{2 8 , 2 9})$, the location of LVOT calcification has been reported as a predictor of PPI in the other studies $(\mathbf{1 9}, \mathbf{3 0})$. LVOT calcification below NCC (19), LCC (30), and RCC (30) were individually reported as the predictor of new PPI. Our analysis revealed the overall LVOT calcification, regardless of the location, as a predictor of new CD, however, the distribution of calcification was not assessed. 
Careful THV sizing and implantation strategy is implicated for the TAVR for BAV anatomy with severe LVOT calcification. The LVOT calcification may increase mechanical stress to the LVOT tissue and conduction system $(\mathbf{1 9}, \mathbf{3 0})$. In theory, this problem might be solved with the high implantation technique because high-implanted THV would have less chance to interact with the conduction system nor the LVOT calcification.

\section{Membranous septum length and bicuspid aortic valve}

The current study demonstrated similar MS length in BAV and TAV patients, unlike the previous study that revealed shorter MS length in BAV than TAV (24). A possible explanation for this discrepancy is the difference in measuring the MS length $(\mathbf{1 8}, \mathbf{2 4})$. We speculate that it is more difficult to control the deployment of the THV due to challenging anatomical features accompanied with BAV such as eccentric device landing zone calcification, asymmetric geometry of the cusps, and concomitant pathologies of the aorta (severe tortuosity, horizontal aorta, and aneurysms) (31 ). Thus, the implantation might be targeted deeper to avoid valve migration or embolization rather than high implantation when the device manipulation is difficult especially in a trans-femoral case. Also, variation of implantation depth was higher in the BAV group (0.59 vs 0.34 ), which might reflect the unstable control of implantation depth compared to TAV. Further studies demonstrating the relation between implantation depth and the safety or the efficacy of high implantation for BAV are warranted.

\section{Limitations}

First, this study had the typical limitation of a retrospective study. The indication of TAVR for bicuspid aortic valve instead of SAVR, the choice of THV type or size may differ among the centers. Second, there have been published two different methods of measuring MS, and the gold standard was still controversial. The results that MS was not significantly different between the 2 groups might be different when the other way is employed. Third, as to clinical outcomes other than CD, the results should be interpreted with care, since the study cohort excluded the patients who potentially develop complications. Two implantation failures and no intraprocedural death were excluded from the BAV cohort, and 2 implantation failures 2 intraprocedural death were excluded from TAV group. Fourth, PS matching was modeled with the TAV cohort from single-center, while the BAV cohort consisted of the patients from 3 centers. Also, even though the PS matching has balanced patient characteristics, several factors were not included in the model and unmeasured confound factors may not be eliminated.

\section{Conclusion}

The combination of the implantation depth at non-coronary cusp and membranous septum length, and severe LVOT calcification were significantly associated with new conduction disturbance following TAVR for bicuspid aortic stenosis with balloon-expandable valve. High implantation technique could be considered to avoid new-onset CD in BAV anatomy.

\section{Data availability}

The data that support the findings of this study are available from the corresponding author, ML, upon reasonable request.

\section{References}

1. Smith CR, Leon MB, Mack MJ, Miller DC, Moses JW, Svensson LG, Tuzcu EM, Webb JG, Fontana GP, Makkar RR, Williams M, Dewey T, Kapadia S, Babaliaros V, Thourani VH, Corso P, Pichard AD, Bavaria JE, Herrmann HC, Akin JJ, Anderson WN, Wang D, Pocock SJ; PARTNER Trial Investigators. Transcatheter versus surgical aortic-valve replacement in high-risk patients. N Engl J Med. 2011;364:218798.

2. Adams DH, Popma JJ, Reardon MJ, Yakubov SJ, Coselli JS, Deeb GM, Gleason TG, Buchbinder M, Hermiller J, Jr, Kleiman NS, Chetcuti S, Heiser J, Merhi W, Zorn G, Tadros P, Robinson N, Petrossian G, Hughes GC, Harrison JK, Conte J, Maini B, Mumtaz M, Chenoweth S, Oh JK; U.S. CoreValve Clinical 
Investigators. Transcatheter aortic-valve replacement with a self-expanding prosthesis. N Engl J Med. 2014;370:1790-8.

3. Mack MJ, Leon MB, Thourani VH, Makkar R, Kodali SK, Russo M, Kapadia SR, Malaisrie SC, Cohen DJ, Pibarot P, Leipsic J, Hahn RT, Blanke P, Williams MR, McCabe JM, Brown DL, Babaliaros V, Goldman S, Szeto WY, Genereux P, Pershad A, Pocock SJ, Alu MC, Webb JG, Smith CR; PARTNER 3 Investigators. Transcatheter Aortic-Valve Replacement with a Balloon-Expandable Valve in Low-Risk Patients. N Engl J Med. 2019;380:1695-705.

4. Popma JJ, Deeb GM, Yakubov SJ, Mumtaz M, Gada H, O'Hair D, Bajwa T, Heiser JC, Merhi W, Kleiman NS, Askew J, Sorajja P, Rovin J, Chetcuti SJ, Adams DH, Teirstein PS, Zorn GL 3rd, Forrest JK, Tchetche D, Resar J, Walton A, Piazza N, Ramlawi B, Robinson N, Petrossian G, Gleason TG, Oh JK, Boulware MJ, Qiao H, Mugglin AS, Reardon MJ; Evolut Low Risk Trial Investigators. Transcatheter Aortic-Valve Replacement with a Self-Expanding Valve in Low-Risk Patients. N Engl J Med. 2019;380:1706-15.

5. Basso C, Boschello M, Perrone C, Mecenero A, Cera A, Bicego D, Thiene G, De Dominicis E. An echocardiographic survey of primary school children for bicuspid aortic valve. Am J Cardiol. 2004;93:661-3.

6. NistriS, BassoC, MarzariC, MorminoP, ThieneG. Frequency of bicuspid aortic valve in young male conscripts by echocardiogram. Am J Cardiol. 2005;96:718-21.

7. Robicsek F, Thubrikar MJ, Cook JW, Fowler B. The congenitally bicuspid aortic valve: how does it function? Why does it fail? Ann Thorac Surg. 2004;77:177-85.

8. Pineda AM, Rymer J, Wang A, Banks AZ, Koweek LH, Plichta R, Williams A, Vavalle JP, Halim S, Kiefer T, Wang A, Gaca J, Hughes GC, Harrison JK. Transcatheter aortic valve replacement for patients with severe bicuspid aortic stenosis. Am Heart J. 2020;224:105-12.

9. J Yoon SH, Bleiziffer S, De Backer O, Delgado V, Arai T, Ziegelmueller J, Barbanti M, Sharma R, Perlman GY, Khalique OK, Holy EW, Saraf S, Deuschl F, Fujita B, Ruile P, Neumann FJ, Pache G, Takahashi M, Kaneko H, Schmidt T, Ohno Y, Schofer N, Kong WKF, Tay E, Sugiyama D, Kawamori H, Maeno Y, Abramowitz Y, Chakravarty T, Nakamura M, Kuwata S, Yong G, Kao HL, Lee M, Kim HS, Modine T, Wong SC, Bedgoni F, Testa L, Teiger E, Butter C, Ensminger SM, Schaefer U, Dvir D, Blanke P, Leipsic J, Nietlispach F, Abdel-Wahab M, Chevalier B, Tamburino C, Hildick-Smith D, Whisenant BK, Park SJ, Colombo A, Latib A, Kodali SK, Bax JJ, Sondergaard L, Webb JG, Lefevre T, Leon MB, Makkar R. Outcomes in Transcatheter Aortic Valve Replacement for Bicuspid Versus Tricuspid Aortic Valve Stenosis. J Am Coll Cardiol. 2017;69:2579-89.

10. Makkar RR, Yoon SH, Leon MB, Chakravarty T, Rinaldi M, Shah PB, Skipper ER, Thourani VH, Babaliaros V, Cheng W, Trento A, Vemulapalli S, Kapadia SR, Kodali S, Mack MJ, Tang GHL, Kaneko T. Association Between Transcatheter Aortic Valve Replacement for Bicuspid vs Tricuspid Aortic Stenosis and Mortality or Stroke. JAMA. 2019;321:2193-202.

11. Waksman R, Craig PE, Torguson R, Asch FM, Weissman G, Ruiz D, Gordon P, Ehsan A, Parikh P, Bilfinger T, Levitt R, Hahn C, Roberts D, Ingram M, Hanna N, Comas G, Zhang C, Ben-Dor I, Satler LF, Garcia-Garcia HM, Shults C, Rogers T. Transcatheter Aortic Valve Replacement in Low-Risk Patients With Symptomatic Severe Bicuspid Aortic Valve Stenosis. JACC Cardiovasc Interv. 2020;13:1019-27.

12. Nazif TM, Dizon JM, Hahn RT, Xu K, Babaliaros V, Douglas PS, El-Chami MF, Herrmann HC, Mack M, Makkar RR, Miller DC, Pichard A, Tuzcu EM, Szeto WY, Webb JG, Moses JW, Smith CR, Williams MR, Leon MB, Kodali SK; PARTNER Publications Office. Predictors and clinical outcomes of permanent pacemaker implantation after transcatheter aortic valve replacement: the PARTNER (Placement of AoRtic TraNscathetER Valves) trial and registry. JACC Cardiovasc Interv. 2015;8:60-9.

13. Nazif TM, Chen S, George I, Dizon JM, Hahn RT, Crowley A, Alu MC, Babaliaros V, Thourani VH, Herrmann HC, Smalling RW, Brown DL, Mack MJ, Kapadia S, Makkar R, Webb JG, Leon MB, Kodali SK. New-onset left bundle branch block after transcatheter aortic valve replacement is associated with adverse 
long-term clinical outcomes in intermediate-risk patients: an analysis from the PARTNER II trial. Eur Heart J. 2019;40:2218-27.

14: Regueiro A, Abdul-Jawad Altisent O, Del Trigo M, Campelo-Parada F, Puri R, Urena M, Philippon F, Rodes-Cabau J. Impact of New-Onset Left Bundle Branch Block and Periprocedural Permanent Pacemaker Implantation on Clinical Outcomes in Patients Undergoing Transcatheter Aortic Valve Replacement: A Systematic Review and Meta-Analysis. Circ Cardiovasc Interv. 2016;9:e003635.

15. Mendiz OA, Noč M, Fava CM, Gutiérrez Jaikel LA, Sztejfman M, Pleskovič A, Gamboa P, Valdivieso LR, Gada H, Tang GHL. Impact of Cusp-Overlap View for TAVR with Self-Expandable Valves on 30-Day Conduction Disturbances. J Interv Cardiol. 2021;9991528.

16. Sammour Y, Banerjee K, Kumar A, Lak H, Chawla S, Incognito C, Patel J, Kaur M, Abdelfattah O, Svensson LG, Tuzcu EM, Reed GW, Puri R, Yun J, Krishnaswamy A, Kapadia S. Systematic Approach to High Implantation of SAPIEN-3 Valve Achieves a Lower Rate of Conduction Abnormalities Including Pacemaker Implantation. Circ Cardiovasc Interv. 2021;14:e009407.

17. Hamdan A, Guetta V, Klempfner R, Konen E, Raanani E, Glikson M, Goitein O, Segev A, Barbash I, Fefer P, Spiegelstein D, Goldenberg I, Schwammenthal E. Inverse Relationship Between Membranous Septal Length and the Risk of Atrioventricular Block in Patients Undergoing Transcatheter Aortic Valve Implantation. JACC Cardiovasc Interv. 2015;8:1218-28.

18. Jilaihawi H, Zhao Z, Du R, Staniloae C, Saric M, Neuburger PJ, Querijero M, Vainrib A, Hisamoto K, Ibrahim H, Collins T, Clark E, Pushkar I, Bamira D, Benenstein R, Tariq A, Williams M. Minimizing Permanent Pacemaker Following Repositionable Self-Expanding Transcatheter Aortic Valve Replacement. JACC Cardiovasc Interv. 2019;12:1796-807.

19. Maeno Y, Abramowitz Y, Kawamori H, Kazuno Y, Kubo S, Takahashi N, Mangat G, Okuyama K, Kashif M, Chakravarty T, Nakamura M, Cheng W, Friedman J, Berman D, Makkar RR, Jilaihawi H. A Highly Predictive Risk Model for Pacemaker Implantation After TAVR. JACC Cardiovasc Imaging. 2017;10:113947.

20. Sievers HH, Schmidtke C. A classification system for the bicuspid aortic valve from 304 surgical specimens. J Thorac Cardiovasc Surg 2007;133: 1226-33.

21. Tops LF, Wood DA, Delgado V, Schuijf JD, Mayo JR, Pasupati S, Lamers FP, van der Wall EE, Schalij MJ, Webb JG, Bax JJ. Noninvasive evaluation of the aortic root with multislice computed tomography implications for transcatheter aortic valve replacement. JACC Cardiovasc Imaging. 2008;1:321-30.

22. Barbanti M, Yang TH, Rodès Cabau J, Tamburino C, Wood DA, Jilaihawi H, Blanke P, Makkar RR, Latib A, Colombo A, Tarantini G, Raju R, Binder RK, Nguyen G, Freeman M, Ribeiro HB, Kapadia S, Min J, Feuchtner G, Gurtvich R, Alqoofi F, Pelletier M, Ussia GP, Napodano M, de Brito FS Jr, Kodali S, Norgaard BL, Hansson NC, Pache G, Canovas SJ, Zhang H, Leon MB, Webb JG, Leipsic J. Anatomical and procedural features associated with aortic root rupture during balloon-expandable transcatheter aortic valve replacement. Circulation. 2013;128:244-53.

23. Kappetein AP, Head SJ, Généreux P, Piazza N, van Mieghem NM, Blackstone EH, Brott TG, Cohen DJ, Cutlip DE, van Es GA, Hahn RT, Kirtane AJ, Krucoff MW, Kodali S, Mack MJ, Mehran R, Rodés-Cabau J, Vranckx P, Webb JG, Windecker S, Serruys PW, Leon MB. Updated standardized endpoint definitions for transcatheter aortic valve implantation: the Valve Academic Research Consortium-2 consensus document. J Am Coll Cardiol. 2012;60:1438-54.

24. Hamdan A, Nassar M, Schwammenthal E, Perlman G, Arow Z, Lessick J, Kerner A, Barsheshet A, Assa HV, Assali A, Aviv Y, Goitein O, Brodov Y, Codner P, Orvin K, Biton D, Klein E, Danenberg H, Finkelstein A, Kornowski R. Short membranous septum length in bicuspid aortic valve stenosis increases the risk of conduction disturbances. J Cardiovasc Comput Tomogr. 2021;15:339-47. 
25. Yoon SH, Lefèvre T, Ahn JM, Perlman GY, Dvir D, Latib A, Barbanti M, Deuschl F, De Backer O, Blanke P, Modine T, Pache G, Neumann FJ, Ruile P, Arai T, Ohno Y, Kaneko H, Tay E, Schofer N, Holy EW, Luk NHV, Yong G, Lu Q, Kong WKF, Hon J, Kao HL, Lee M, Yin WH, Park DW, Kang SJ, Lee SW, Kim YH, Lee CW, Park SW, Kim HS, Butter C, Khalique OK, Schaefer U, Nietlispach F, Kodali SK, Leon MB, Ye J, Chevalier B, Leipsic J, Delgado V, Bax JJ, Tamburino C, Colombo A, Søndergaard L, Webb JG, Park SJ. Transcatheter Aortic Valve Replacement With Early- and New-Generation Devices in Bicuspid Aortic Valve Stenosis. J Am Coll Cardiol. 2016;68:1195-205.

26. Mangieri A, Tchetchè D, Kim WK, Pagnesi M, Sinning JM, Landes U, Kornowski R, De Backer O, Nickenig G, Ielasi A, De Biase C, Søndergaard L, De Marco F, Montorfano M, Chiarito M, Regazzoli D, Stefanini G, Presbitero P, Toggweiler S, Tamburino C, Immè S, Tarantini G, Sievert H, Schäfer U, Kempfert J, Wöehrle J, Gallo F, Laricchia A, Latib A, Giannini F, Colombo A. Balloon Versus Self-Expandable Valve for the Treatment of Bicuspid Aortic Valve Stenosis: Insights From the BEAT International Collaborative Registrys. Circ Cardiovasc Interv. 2020;13:e008714.

27. Tchetche D, de Biase C, van Gils L, Parma R, Ochala A, Lefevre T, Hovasse T, De Backer O, Sondergaard L, Bleiziffer S, Lange R, Kornowski R, Landes U, Norgaard BL, Biasco L, Philippart R, Molina-Martin de Nicolas J, Mylotte D, Lemee C, Dumonteil N, Van Mieghem NM. Bicuspid Aortic Valve Anatomy and Relationship With Devices: The BAVARD Multicenter Registry. Circ Cardiovasc Interv. 2019;12:e007107.

28. Seiffert M, Fujita B, Avanesov M, Lunau C, Schön G, Conradi L, Prashovikj E, Scholtz S, Börgermann J, Scholtz W, Schäfer U, Lund G, Ensminger S, Treede H. Device landing zone calcification and its impact on residual regurgitation after transcatheter aortic valve implantation with different devices. Eur Heart $\mathrm{J}$ Cardiovasc Imaging. 2016;17:576-84.

29. Okuno T, Asami M, Heg D, Lanz J, Praz F, Hagemeyer D, Brugger N, Gräni C, Huber A, Spirito A, Räber L, Stortecky S, Windecker S, Pilgrim T. Impact of Left Ventricular Outflow Tract Calcification on Procedural Outcomes After Transcatheter Aortic Valve Replacement. JACC Cardiovasc Interv. 2020;13:1789-99.

30. Mauri V, Reimann A, Stern D, Scherner M, Kuhn E, Rudolph V, Rosenkranz S, Eghbalzadeh K, Friedrichs K, Wahlers T, Baldus S, Madershahian N, Rudolph TK. Predictors of Permanent Pacemaker Implantation After Transcatheter Aortic Valve Replacement With the SAPIEN 3. JACC Cardiovasc Interv. 2016;9:2200-9.

31. Kim WK, Bhumimuang K, Renker M, Fischer-Rasokat U, Möllmann H, Walther T, Choi YH, Nef H, Hamm CW. Determinants of paravalvular leakage following transcatheter aortic valve replacement in patients with bicuspid and tricuspid aortic stenosis. Eur Heart J Cardiovasc Imaging. 2021:jeab011.

\section{Figure Legends:}

\section{Figure 1. Study flow chart}

The incidence and predictors of new-onset CD were identified from the BAV cohort (169 patients) and the incidence of new-onset CD was identified from the matched cohort (166 pairs).

$\mathrm{AS}=$ aortic stenosis; $\mathrm{CD}=$ conduction disturbance; $\mathrm{CT}=$ Computed Tomography; PPI = permanent pacemaker implantation; TAVR $=$ transcatheter aortic valve replacement.

\section{Figure 2. The measurement of implantation depth}

Implantation depth was defined as the distance between the bottom of the non-coronary cusp to the ventricular end of the valve stent frame in the final angiogram. Implantation view (3 cusp view) was employed to measure the depth, but the attending physician can be adjusted it.

Figure 3. The duration from the TAVR to the pacemaker implantation.

This figure shows the duration from the TAVR to the permanent pacemaker implantation.

TAVR $=$ transcatheter aortic valve replacement. 
Figure 4. Multivariate analysis for new-onset conduction disturbance after TAVR.

Multivariate analysis for new-onset conduction disturbance after TAVR. Univariate analysis was shown in Supplemental table 1 .

$\mathrm{CABG}=$ coronary artery bypass graft $\mathrm{CI}=$ confidence interval; LVOT $=$ left ventricular outflow tract; MS $=$ membranous septum; TAVR $=$ transcatheter aortic valve replacement.

Figure 5. Plotting of the distribution of implantation depth and membranous septum length.

This figure plots the distribution of implantation depth and MS length, and the red color indicates the newonset CD. The black line divided the patients into two groups (Implantation depth $>$ MS and implantation depth [?] MS).

$\mathrm{CD}=$ conduction disturbance; $\mathrm{MS}=$ membranous septum length .

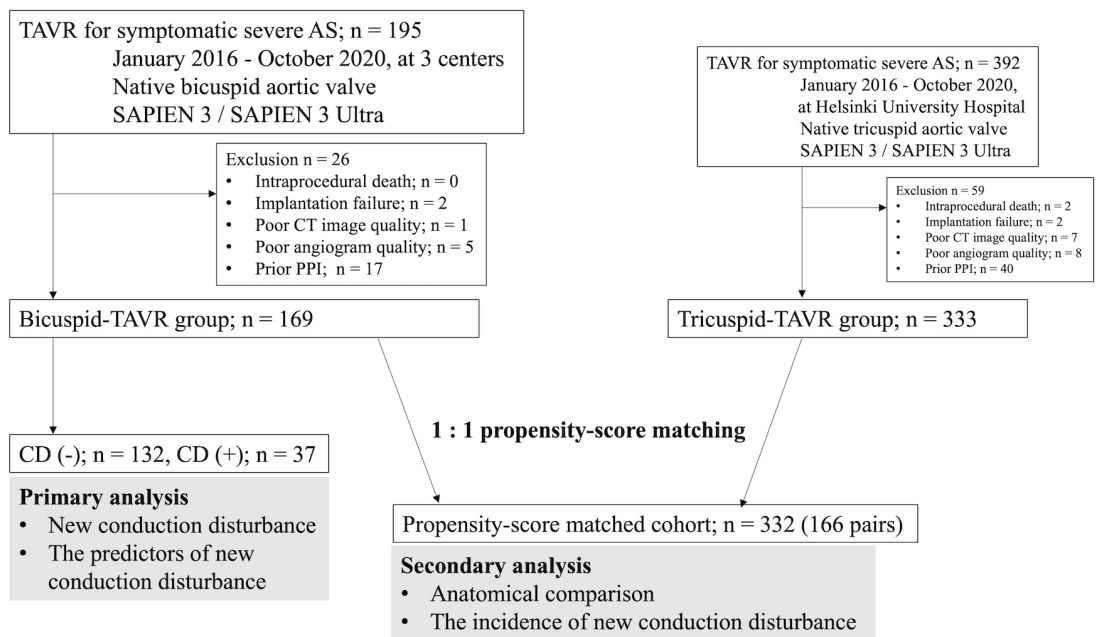




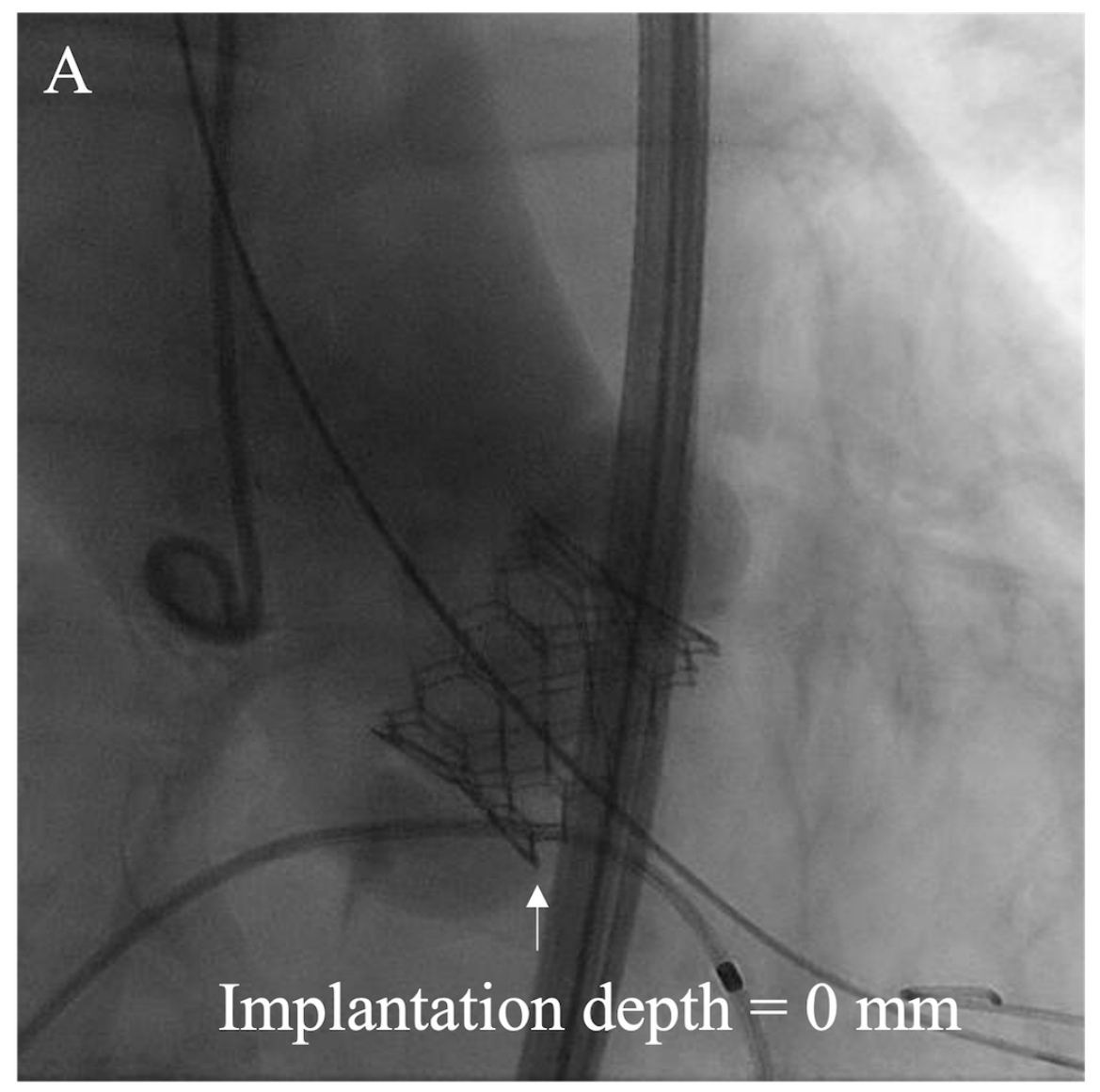




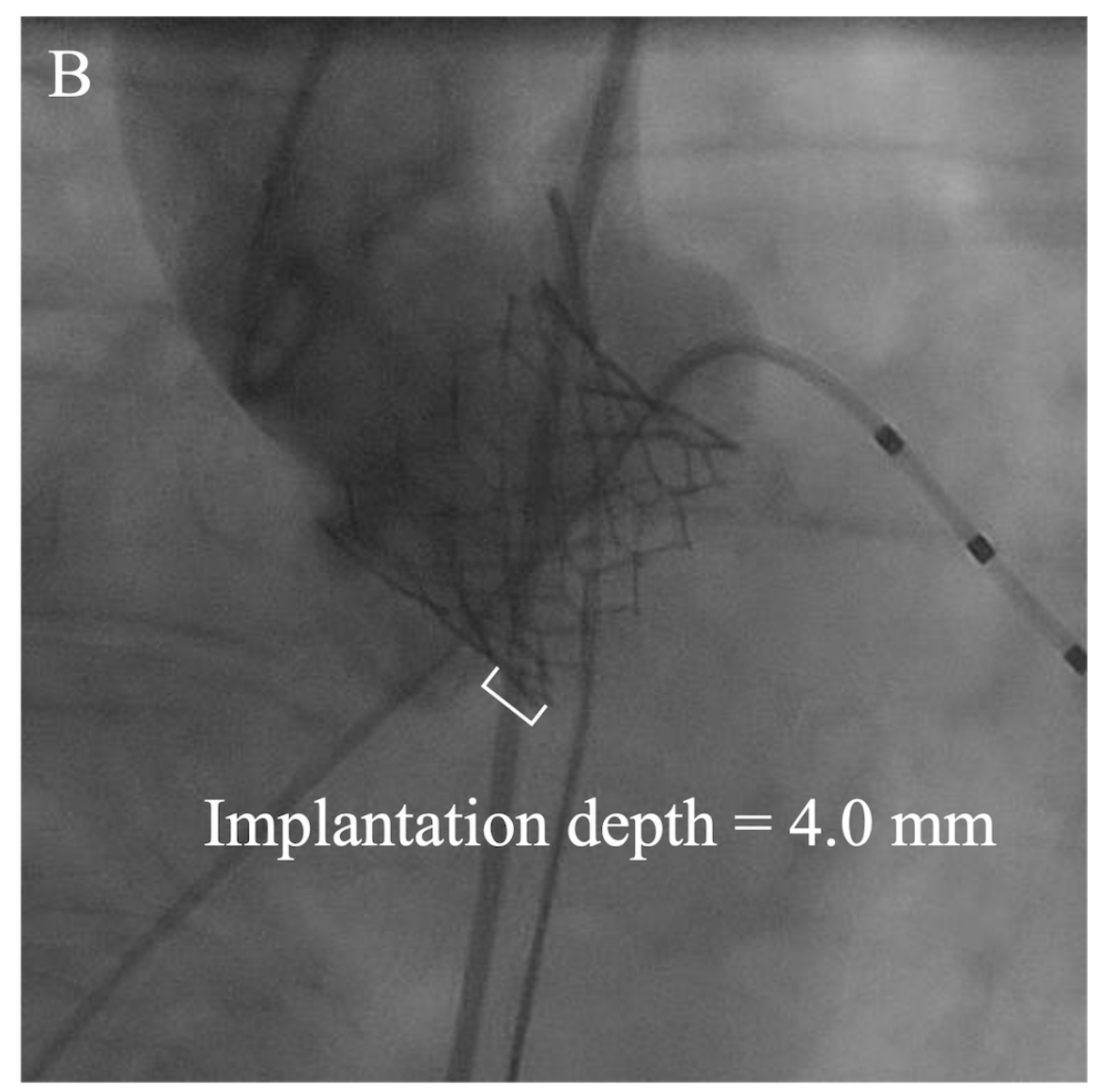



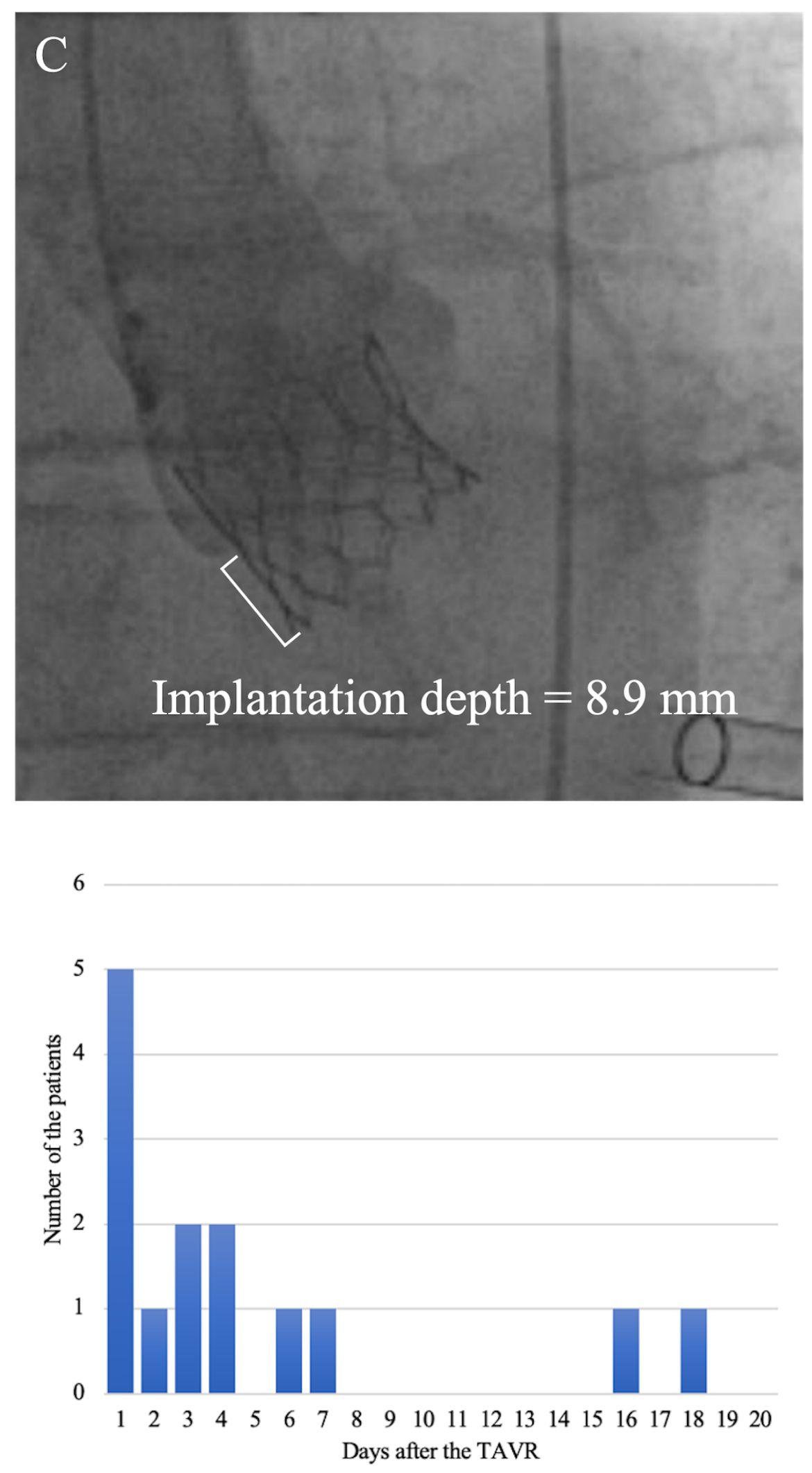

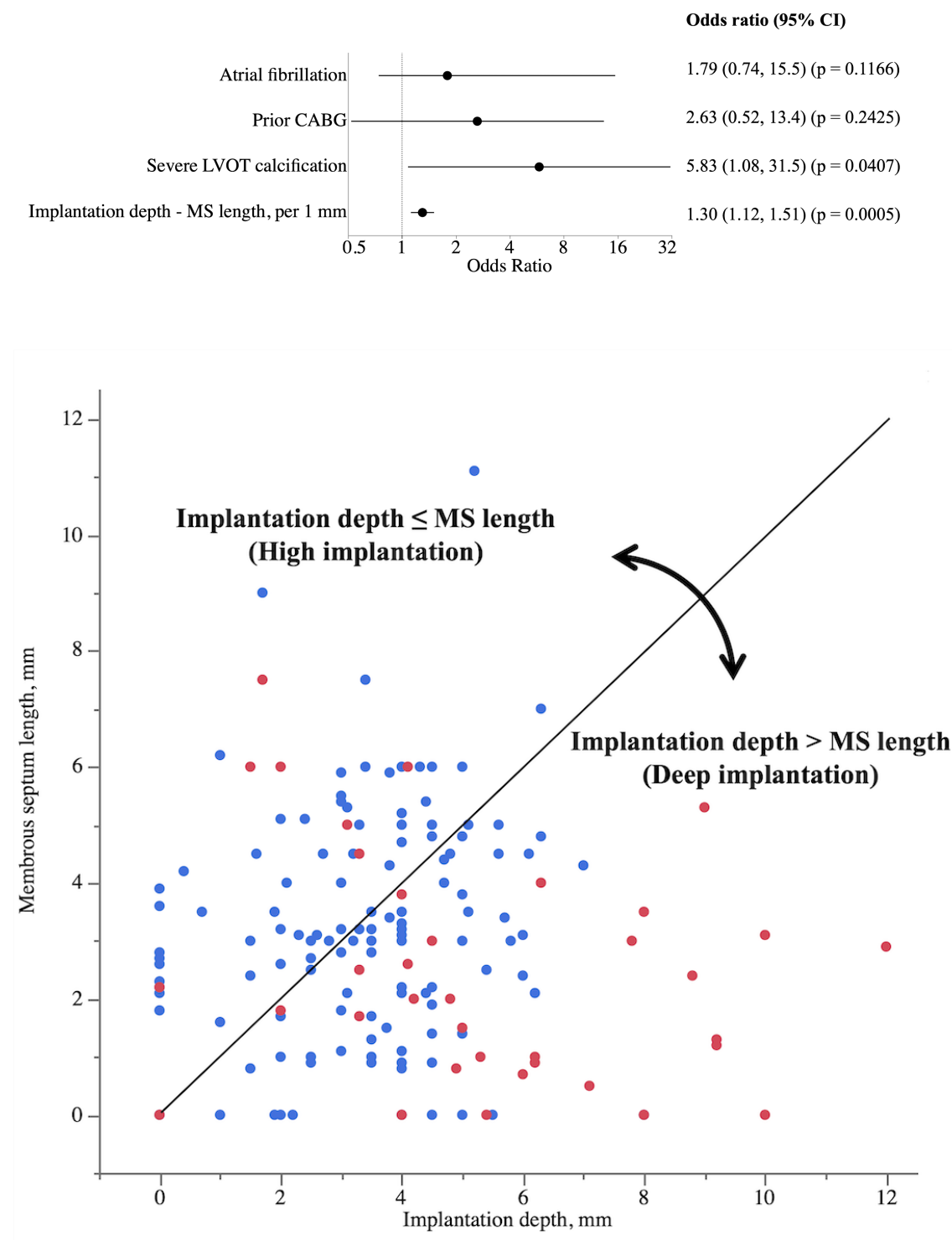

\section{Hosted file}

Bicuspid_Tables_Main_17112021.docx available at https://authorea.com/users/449563/ articles/548070-predictors-of-conduction-disturbances-after-transcatheter-aortic-valveimplantation-with-balloon-expandable-valve-for-bicuspid-aortic-valve-stenosis 